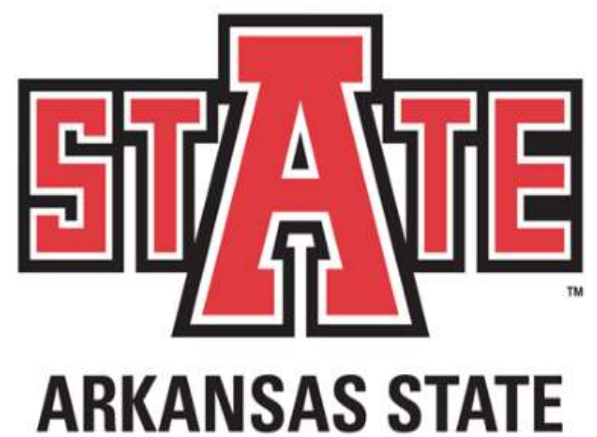

U N I VER S I T Y

ACS Spring National Meeting \& Expo, 2020

Adsorption of Catechol/Hydroquinone on $\mathrm{TiO}_{2}$ and Iron(III) Oxide

Kotaiba Abugazleh

Environmental Science Program 


\section{Motivation of Research}

- The problem of environmental pollution is increasing and its impacts are touching down everywhere.

- Organic pollutants such as PCPs have many applications in human and industrial activities. 


\section{Impact of Environmental Pollution}

\section{Warmer, Warmer Everywhere}

Nearly every region of the globe saw warmer than average temperatures last year.

\section{LAND AND OCEAN TEMPERATURE PERCENTILES}

Jan.-Dec. 2017

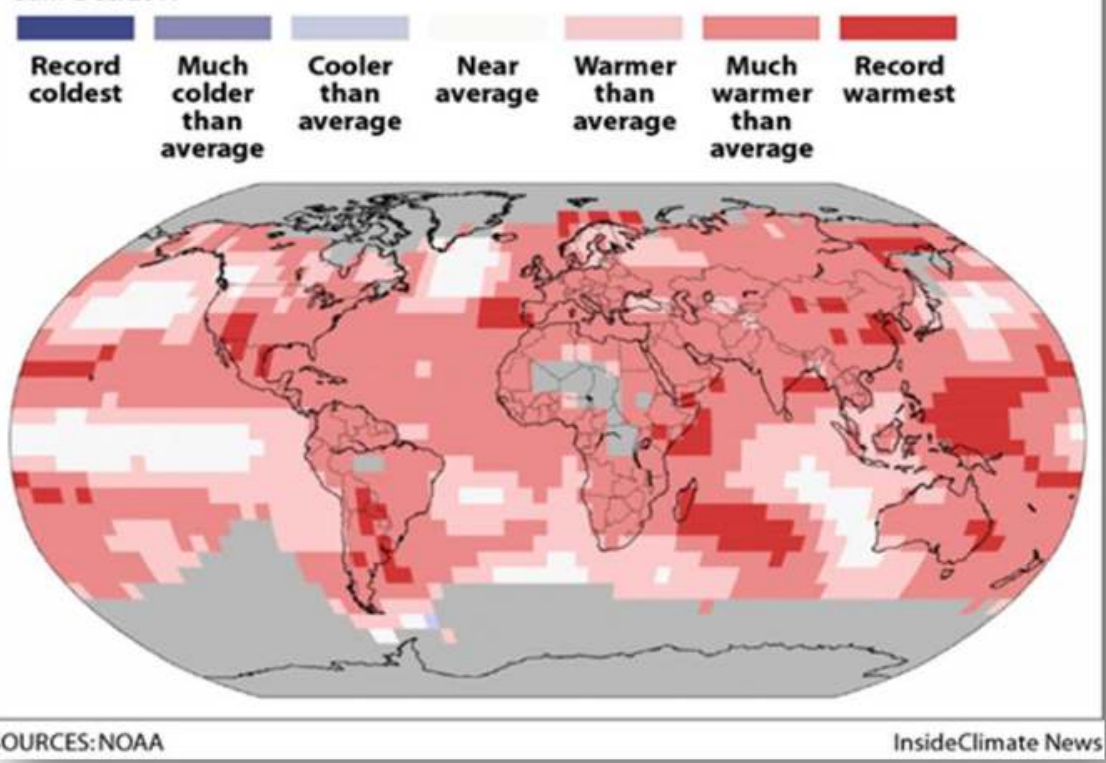

\section{Global water distribution}

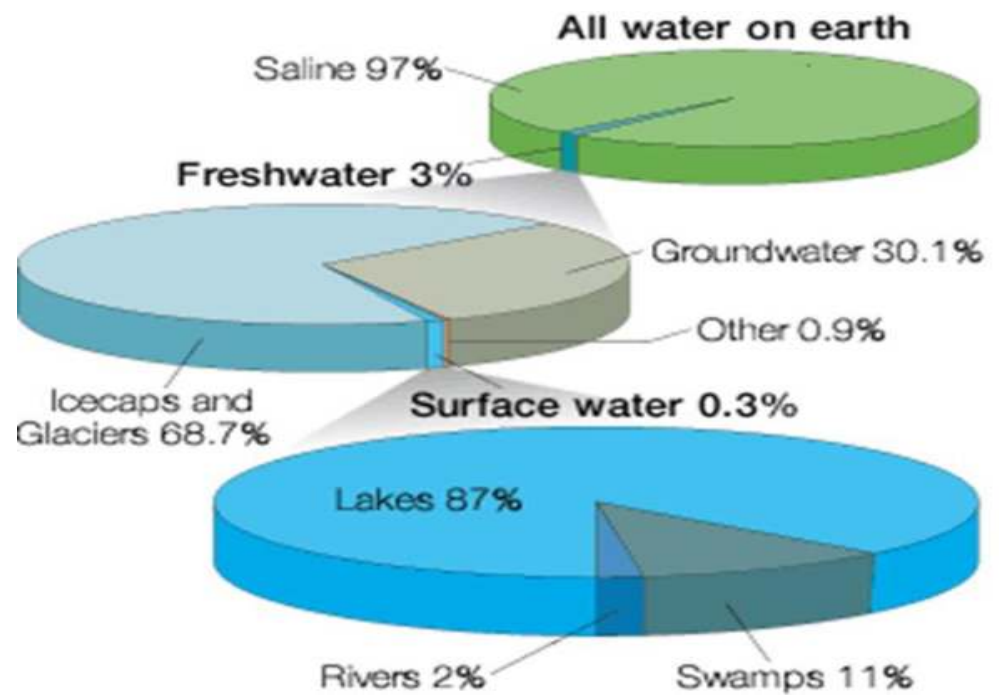




\section{Environmental Pollution}

- Any undesirable change in physical, chemical, or biological characteristics of any component of the environment.

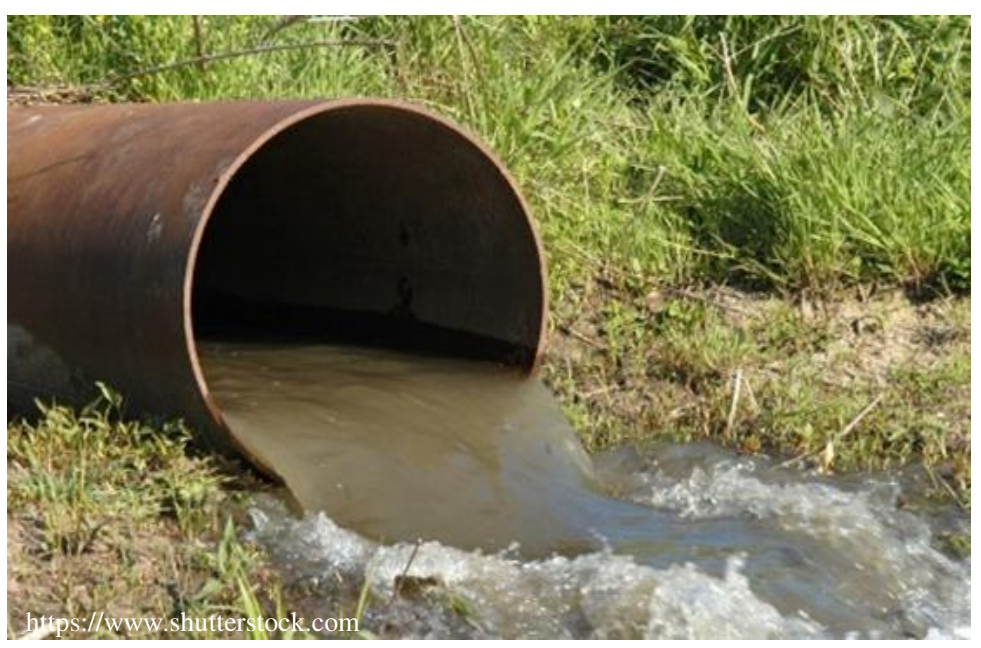

- Water Pollution

Air Pollution

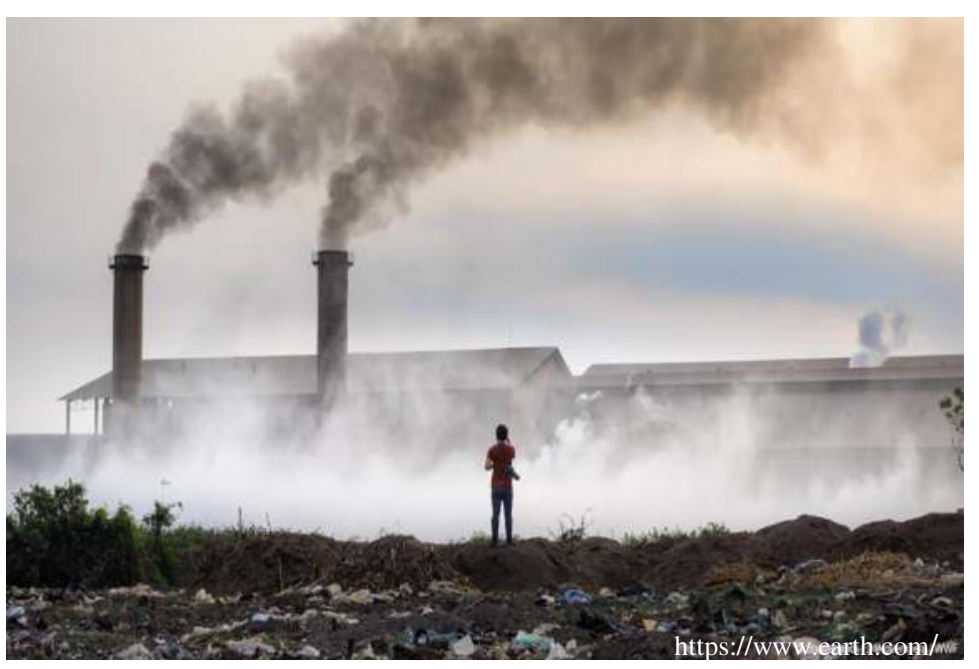




\section{Objectives of Research}

- Investigate adsorption characteristics of organic pollutants (Catechol, Hydroquinone) on the surface of adsorbents (Titanium dioxide, Iron oxides) in aqueous solutions.

- Test the effectiveness of Titanium dioxide $\left(\mathrm{TiO}_{2}\right)$ and Iron oxide $\left(\mathrm{Fe}_{2} \mathrm{O}_{3}\right)$ as adsorbents for the Hydroquinone and Catechol as pollutants in aqueous solutions. 


\section{Spectroscopy Techniques used in this research}

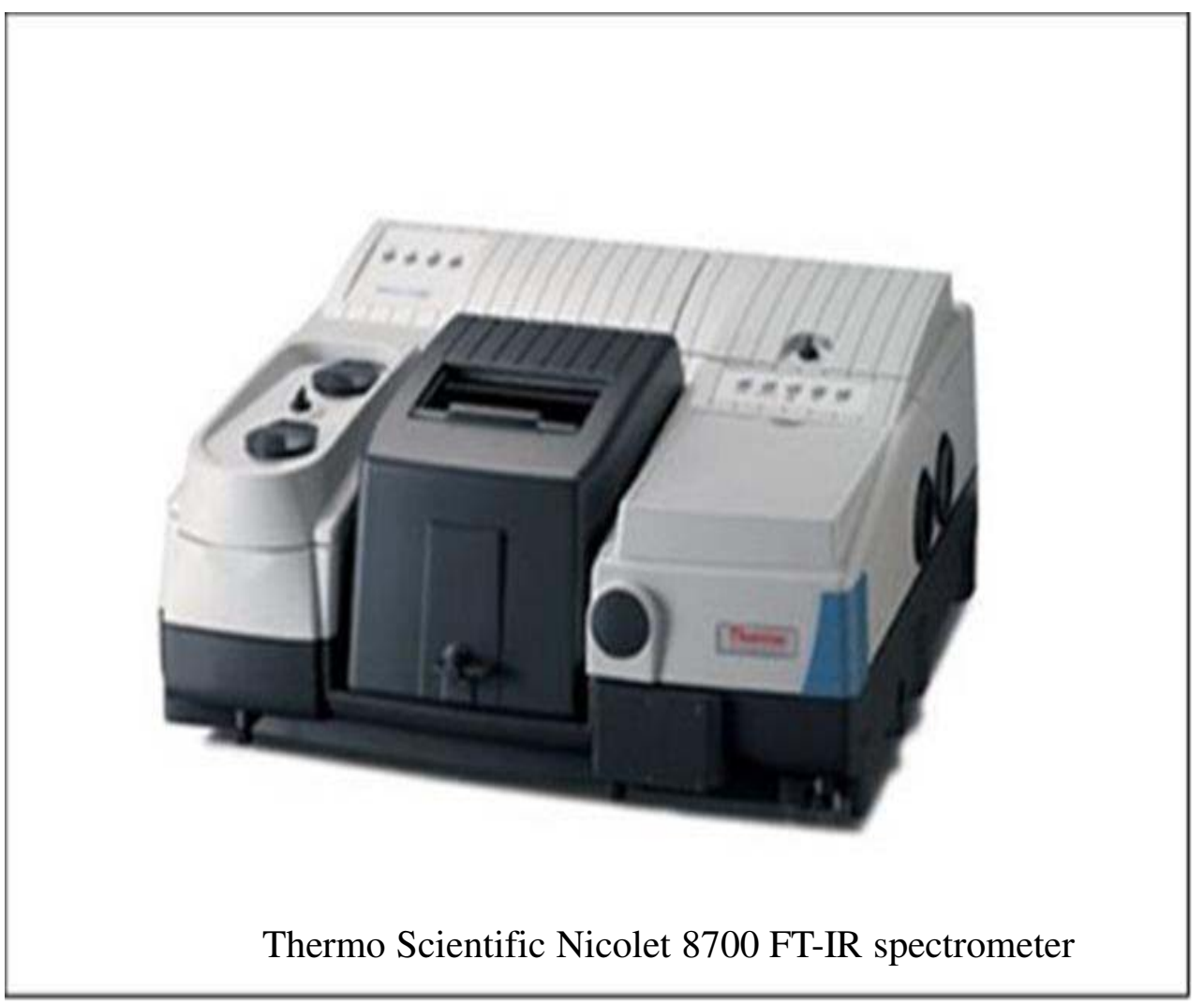

- Volatile chemicals.

- Separate complex mixtures. 


\section{Tested Pollutants}

- Catechol $\mathrm{C}_{6} \mathrm{H}_{6} \mathrm{O}_{2}$

$\square$ Uses:

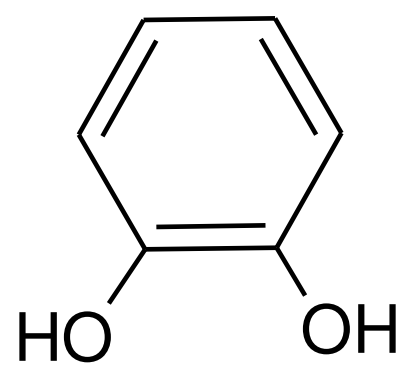

- Photographic developer and fur/hair dyes.

- Pharmaceuticals and PCPs

- Antioxidant in perfumes.

\section{- Harmful effects}

- Severe skin burns.

- Hypertension.

- Animal carcinogen if swallowed.
- Hydroquinone $\mathrm{C}_{6} \mathrm{H}_{6} \mathrm{O}_{2}$ $\square$ Uses:

- Skin bleaching agent, resin coating in cans.

- Intermediate to produce antioxidants for rubber and food.

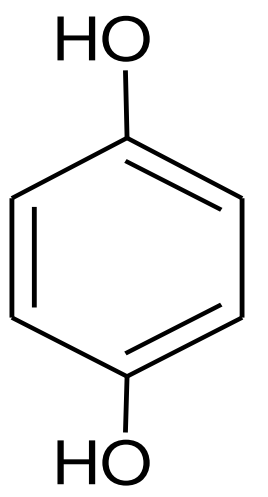

$\square$ Harmful effects

- Enhance carcinogenic risk by generating DNA damage.

- Compromise immune system. 


\section{Tested Oxides}

$>$ Titanium Dioxide $\left(\mathrm{TiO}_{2}\right)$

ㄱoperties:

- High melting and boiling points.

- Insoluble in water.

- UV light resistance.

- Large Surface area.

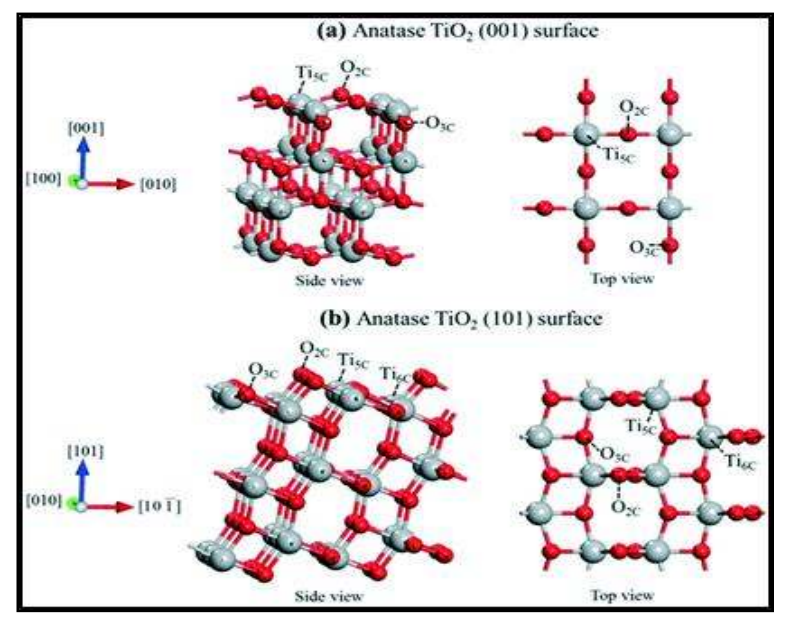

Source: Huang et al.(2016) Promotional effect of the $\mathrm{TiO}_{2}(001)$

\section{$>$ Iron (III) oxide $\left(\mathrm{Fe}_{2} \mathrm{O}_{3}\right)$}

口 Properties:

- High melting and boiling points.

- Magnetic properties.

- Hardness and elastic.

- Large Surface area.

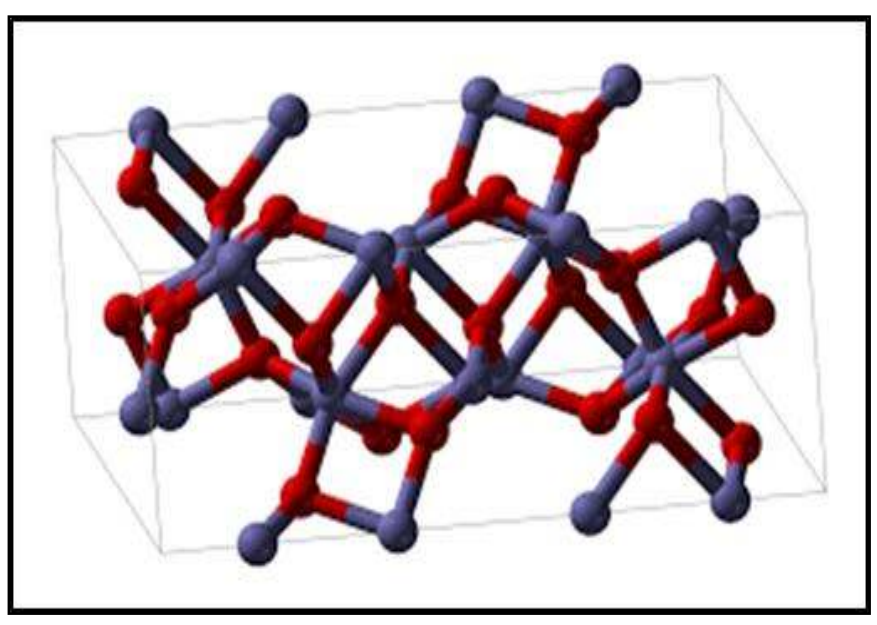

Source: www.webelements.com/ 


\section{Equipment and Materials}

- Thermo Nicolet 8700 Fourier-Transform Infrared Spectrometer (FT-IR) equipped with:

- ZnSe Attenuated Total-Reflection (ATR) crystal.

- HgCdTe (MCT) detector cooled by liquid nitrogen.
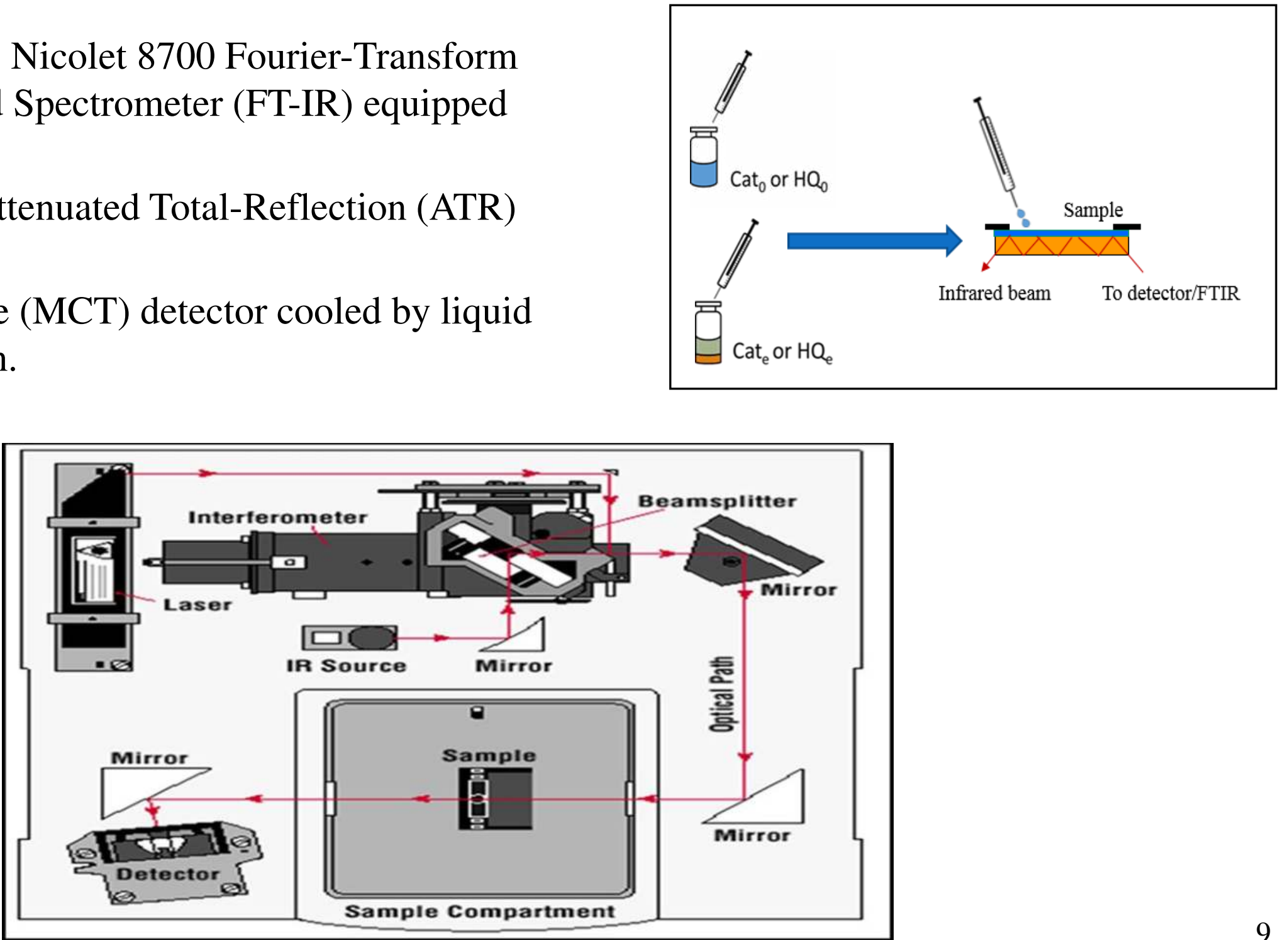


\section{Calibration Data}
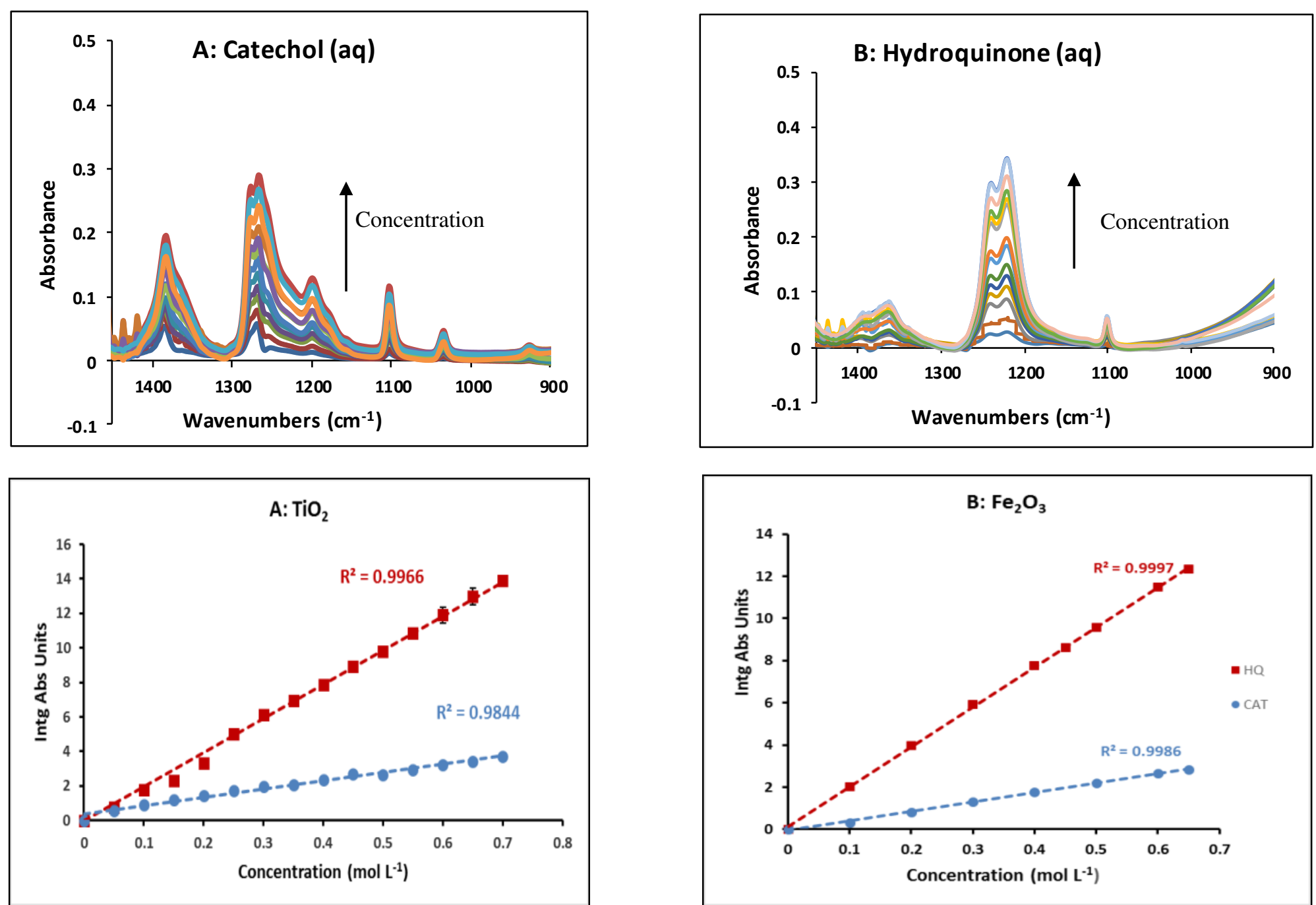


\section{Adsorption Equilibrium}

- Adsorption vs. Absorption

- Adsorption is accumulation of molecules on a surface (a surface layer of molecules) in contact with a gas or water phase.

- Absorption is dissolution of molecules within a phase, e.g., within an organic phase in contact with an air or water phase.

- An adsorption isotherm is a curve explained by a $\mathrm{q}_{\mathrm{e}}$ vs. $\mathrm{C}_{\mathrm{e}}$ relationship at equilibrium.

- Adsorption isotherm can take multiple forms.

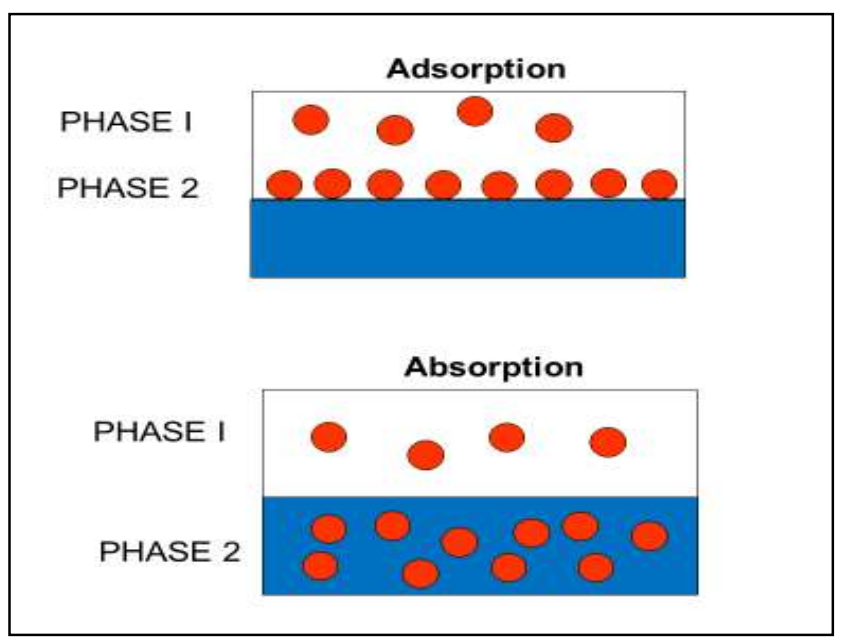

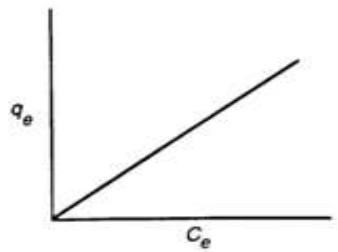

(a) Linear

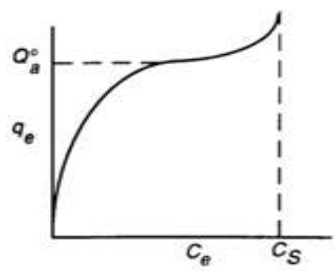

(c) BET

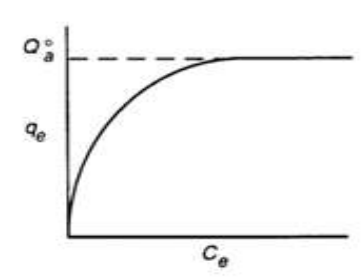

(b) Langmuir

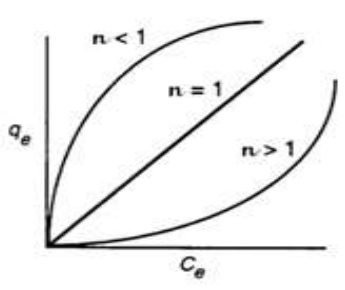

(d) Freundlich 


\section{Adsorption Capacity}

- To identify the maximum adsorption capacity of the oxide $\left(\mathrm{TiO}_{2}, \mathrm{Fe}_{2} \mathrm{O}_{3}\right)$, the two most common adsorption isotherms, Freundlich and Langmuir isotherms, were fitted to data for both HQ and CAT.

- The isotherm with the highest combined $\mathrm{R}^{2}$ was used as the isotherm that best represents the adsorption characteristics.

A) Freundlich

$$
q_{e}=K_{f} C_{e}{ }^{1 / n}
$$

- Heterogeneous surface.

- Assumes non-equivalent sites

- Very empirical

- Provides probability of adsorption

Freundlich linear form :

$$
\log \left(q_{e}\right)=\log \left(K_{f}\right)+\frac{1}{n} \log \left(C_{e}\right)
$$

B) Langmuir

$$
q_{e=} \frac{b \cdot C_{e} \cdot Q_{o}}{1+b C_{e}}
$$

- Homogeneous surface.

- Assumes limited equivalent sites.

- Assumes monolayer coverage.

- Has a rational basis.

Langmuir linear form:

$$
\frac{1}{q_{e}}=\frac{1}{Q_{o}}+\frac{1}{b Q_{o} C_{e}}
$$




\section{Adsorption Isotherm}
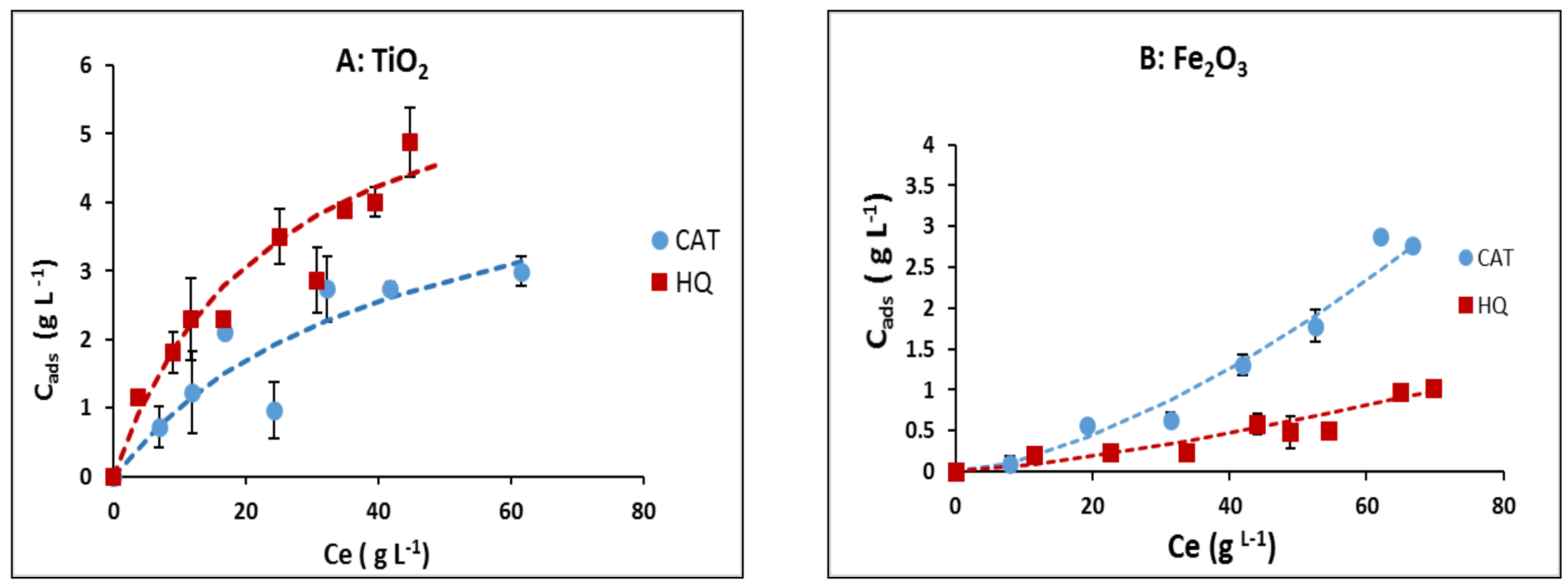

\section{$\mathbf{R}^{2}$ Value}

$\mathrm{TiO}_{2}$

\section{$\mathrm{Fe}_{2} \mathrm{O}_{3}$}

Catechol

Hydroquinone

Catecho

Hydroquinone

\begin{tabular}{ccccc} 
Langmuir & 0.94 & 0.91 & 0.68 & 0.06 \\
Freundlich & 0.47 & 0.92 & 0.98 & 0.95 \\
\hline
\end{tabular}




\section{Adsorption kinetics}

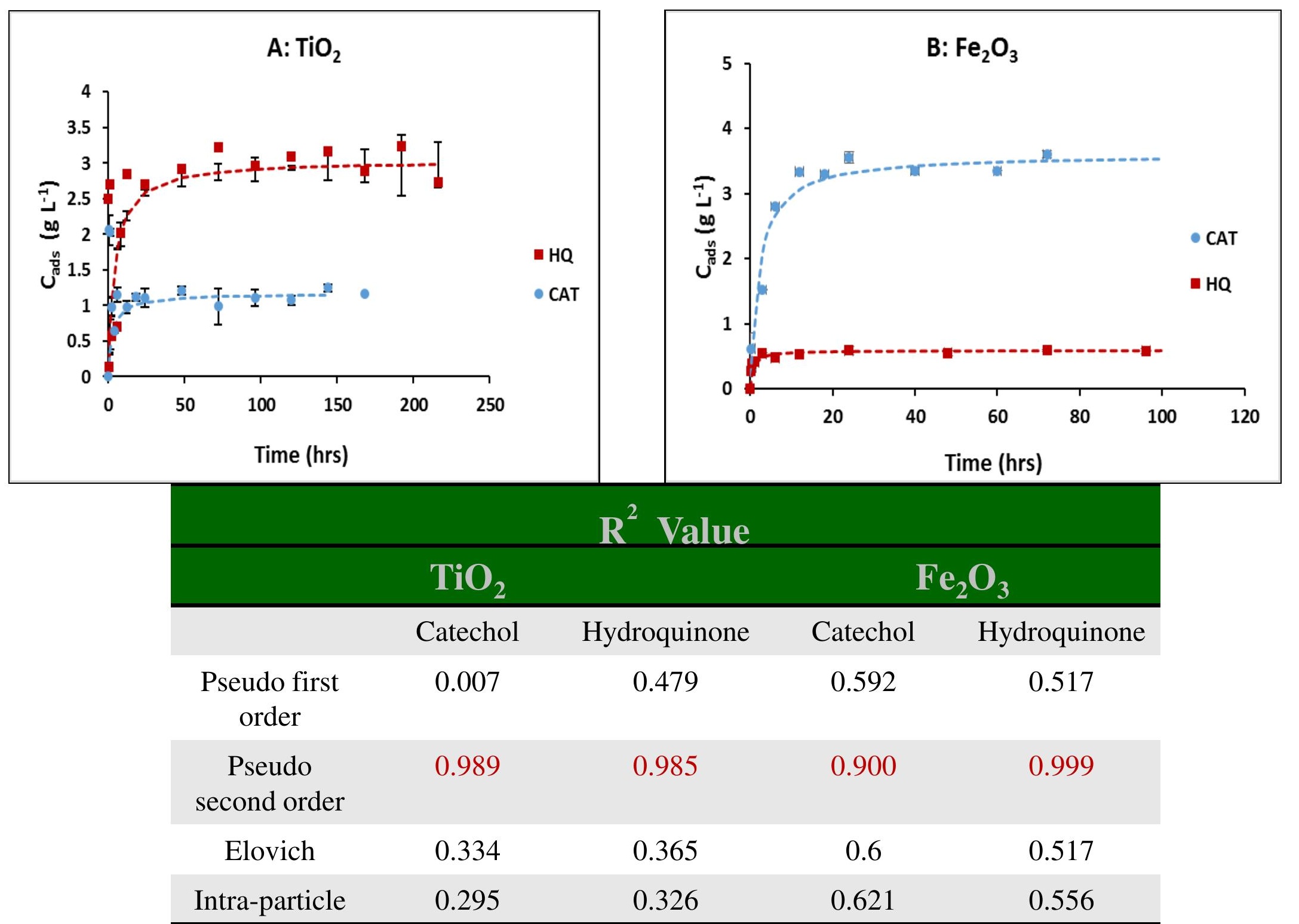




\section{Adsorption pH}

- Point of zero charge (pzc): The $\mathrm{pH}$ where the net total particle charge is zero is called the point of zero charge.
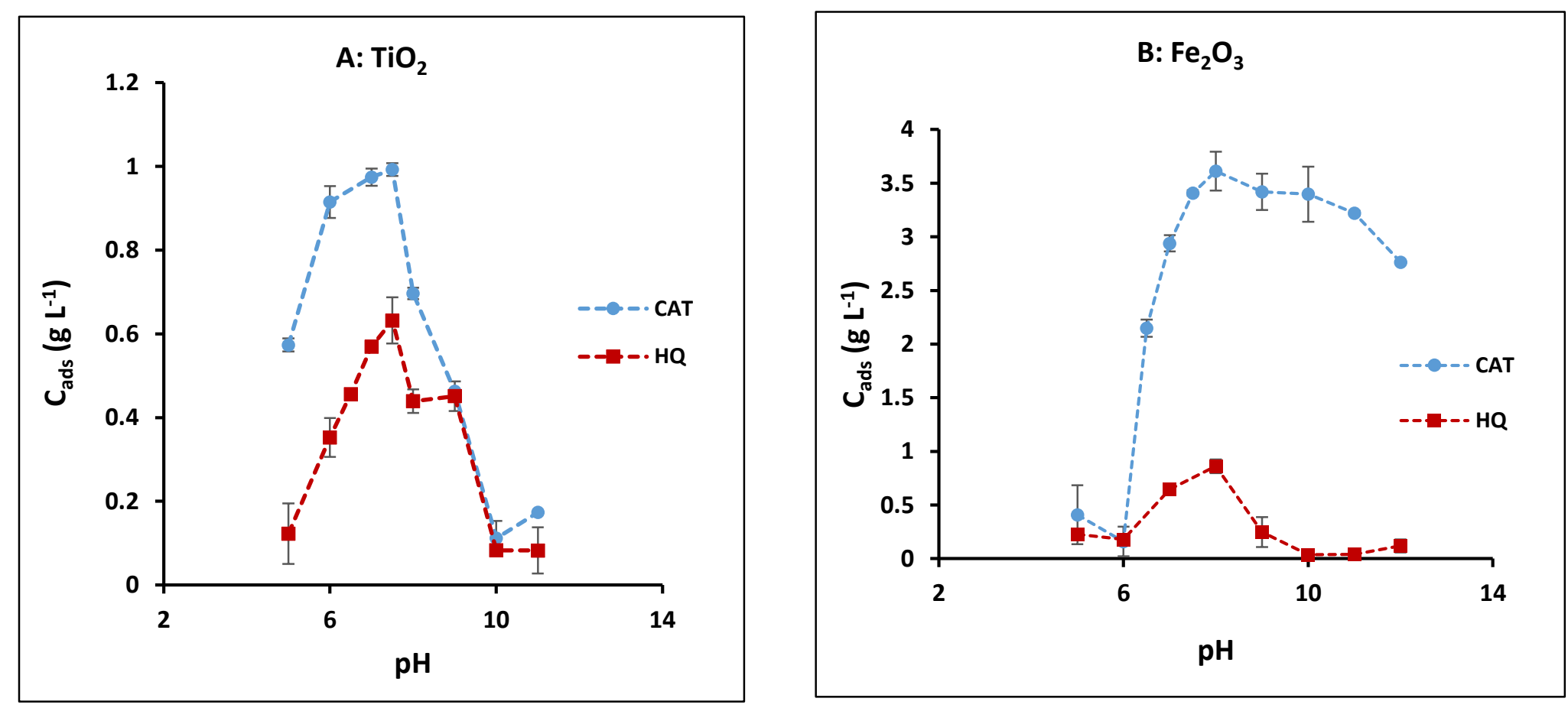

- Positive or negative charged surface of $\mathrm{TiO}_{2} / \mathrm{Fe}_{2} \mathrm{O}_{3}$ which determined by the solutions $\mathrm{pH}$ and their $\mathrm{pHpzc}$. 


\section{Conclusion}

- Using $\mathrm{Fe}_{2} \mathrm{O}_{3}$, CAT and HQ follow Freundlich isotherm, while using $\mathrm{TiO}_{2}$ the Langmuir model was the best fit for CAT and HQ .

- This may be due to:

- Position of $\mathrm{OH}$ and nature of ring influence binding mode on solid surface (geometry of CAT and HQ ).

- $\mathrm{TiO}_{2}$ is seen as a good adsorbent for Catechol and Hydroquinone (Langmuir adsorption isotherm), indicating a strong chemical binding to the surface, lending Cat /HQ ideal to be a removed by $\mathrm{TiO}_{2}$ from wastewater 